\title{
Characterization of a High Efficiency Pilot Plant Wet Scrubber with Internals for Fly Ash Removal
}

\author{
A. Biswas ${ }^{\mathrm{a}}$, B. Rajmohan ${ }^{\mathrm{a}}$, C.R. Mohanty ${ }^{\mathrm{b}}$ and B.C. Meikap ${ }^{\mathrm{a}, *}$ \\ ${ }^{a}$ Department of Chemical Engineering, Indian Institute of Technology Kharagpur \& ${ }^{b}$ State Pollution Control Board, \\ Orissa, India
}

\begin{abstract}
Removal of fly ash using wet scrubbers is widely used in the small and medium scale industries. Among the wet scrubbing methods, spray column falls into the simplest type category for its simple construction and various advantages. A novel pilot plant wet scrubber has been conceived, designed and fabricated. This paper distinctly focuses on the detailed design and fabrication of the ejector, which has been used to prepare fly ash-air mixture in the laboratory. A detail experimental investigation has been carried out to characterize the system. Studies indicate very encouraging result. The size analysis of the fly ash sample along with efficiency of fly ash removal in the wet scrubber has critically been examined. It has been found that the present system yielded mentionable high efficiency for the scrubbing of fly ash. In most of the cases, the efficiency lies between $70 . \%$ and $90 . \%$. The maximum efficiency obtained is above $90 \%$.
\end{abstract}

Keywords: Fly ash, ejector, spray column, droplets, sparger, residence time, scrubbing efficiency.

\section{INTRODUCTION}

Air pollution is increasing at an alarming rate all over the world due to rapid industrialization in the recent years. The emission of particulate matter associated with various types of gases like $\mathrm{SO}_{2}, \mathrm{NO}_{\mathrm{x}}$ etc is a matter of great concern regarding air pollution. The effects of these pollutants are individually very severe and become much more severe when particulate matters come in contact with other gases, because as their additive effect is much more stronger. (Meikap et al. 2000) [1]. This synergism modified effects have motivated the public and private sector industries to work out a reliable background information, enforceable regulations and viable control options for the particulate emissions. The increasingly stringent compliance requirements based on the synergism modified standard have brought tremendous constraints on the industries to control the particulate emission. Day by day, the rules and the guidelines are becoming stringent due to the rapid deteriorating condition of the environment. Therefore; U.S. EPA has restricted the maximum particulate emission limits from coal fired thermal power plants to 22.65g per 0.294 MW (EPA, 1997) [2]. The existing emission standard for particulate matter in India is $0.150 \mathrm{~g} / \mathrm{Nm}^{3}$, where the proposed World Bank standard is still stringent with a value of $0.050 \mathrm{~g} / \mathrm{Nm}^{3}$ (World Bank Guidelines, 1995) [3]. So, compliance with the regulations as well as the optimization for cost effective control methods both have become equally important.

The conventional processes like ESP, cyclone, bag filters, dry processes etc. in use are neither cost effective nor can be used in small or medium scale industries due to high maintenance problems. The use of scrubbers as particulate

*Address correspondence to this author at the Department of Chemical Engineering, Indian Institute of Technology Kharagpur, India; Fax: +913222-282250; E-mail: bcmeikap@che.iitkgp.ernet.in control devices has become common in small and medium scale industries. Scrubbers without any column internals e.g. spray scrubbers are widely used and found to have good results in this field (Meikap et al. 2004, Kohl and Reisenfeld, 1985) $[4,5]$. Early studies on particulate scrubbing reveal that cyclonic spray scrubbing can achieve better results than venturies if the droplet size is reduced to $100 \mu \mathrm{m}$ or lower for capturing particles in the sub-micron range. However, droplets with diameter below $100 \mu \mathrm{m}$ are very difficult to produce (Brandt, 1952) [6]. Burkholz (1989) [7] also reported that maximum particle collection efficiency is achieved in a spray scrubber for droplet size ranging from 25 to $50 \mu \mathrm{m}$ at very high velocities ( 5 to $80 \mathrm{~m} / \mathrm{sec}$ ) for particles with diameter ranging from 1.3 to $3 \mu \mathrm{m}$. Further, literatures reveal that many multistage scrubbers have been attempted for particulate control. However, scrubber with internals does not seem to gain importance (Meikap et al. 2002a 2002b, 2002c) [8, 9, 10]. Therefore an attempt has been made to develop a wet scrubber with internals having advantages like less maintenance due to simple construction and no problem with sealing due to the absence of moving parts, excellent heat transfer properties and easy temperature control and low initial costs. Scrubbing with cooling due to droplet evaporation is one of the main characteristics of spray scrubber. Hence the present work is the design and fabrication of the wet scrubber along with the performance study of the scrubber with respect to removal of the fly ash.

Fly ash is defined as the finely divided residue resulting from the industrial operations. The fly ash can be classified in two basic categories like; (a) Class F fly ash produced by burning anthracite and bituminous coal. (b) Class C fly ash produced by burning lignite or sub-bituminous coal. Difference between class $\mathrm{F}$ and class $\mathrm{C}$ fly ash occurs due to difference in content of $\mathrm{Ca}, \mathrm{SiO}_{2}, \mathrm{Al}_{2} \mathrm{O}_{3}$ and iron in the fly ash. Regarding treatment, for class $\mathrm{C}$ fly ash, hydration is easy but for class F fly ash, addition of lime is necessary for hydration (Meikap et al. 2002) [11]. 
Fig. (1) shows the typical composition of fly ash. Fly ash mainly contains elements like Titanium, Barium, Sodium, Phosphorus, Manganese, Vanadium, Zinc, Copper, Chromium, Cobalt, Silicon, Beryllium, Aluminum, Iron, Cadmium, Potassium, Magnesium etc.

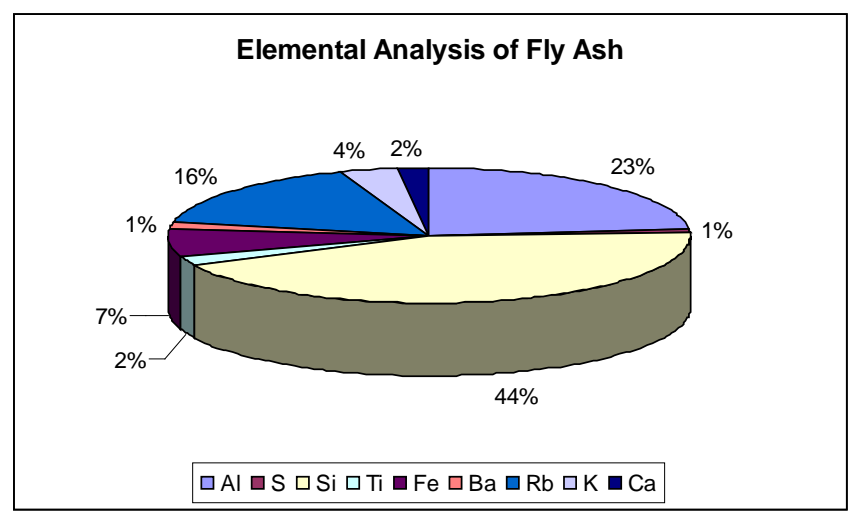

Fig. (1). Composition of fly ash (oxides of various elements).

\section{METHODS AND MATERIALS}

Figs. (3 and 4) show the schematic diagram of the experimental setup. The set up mainly consist of Spray column, Water and air supply system, Fly ash mixing system and their necessary pipe line connections. The spray column consists of a vertical cylindrical Perspex column $0.4550 \mathrm{~m}$ in diameter and $1.275 \mathrm{~m}$ in height. This cylindrical section is fitted onto a fructo-conical bottom of mild steel with a vertical height $0.395 \mathrm{~m}$ and slant height of $0.3937 \mathrm{~m}$ at the top and bottom of the section. At the bottom most section of the cylindrical column and just above the fructo-conical section, there is an antenna type of sparger of $1.6 \mathrm{~mm}$ diameter and consisting of 144 holes (each hole has $3.17 \times 10^{-3} \mathrm{~m} \mathrm{BSW}$ grade) for allowing the fly ash mixed air stream to enter the spray column. This antenna sparger is connected to the inlet pipe supplying the gas stream. At the bottom of the column an outlet is provided to drain away the water.

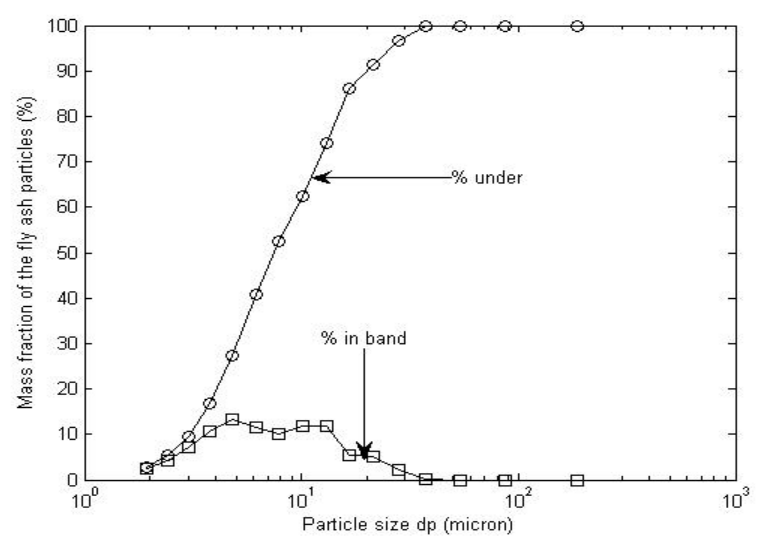

Fig. (2). Typical particle size distribution of fly ash sample.

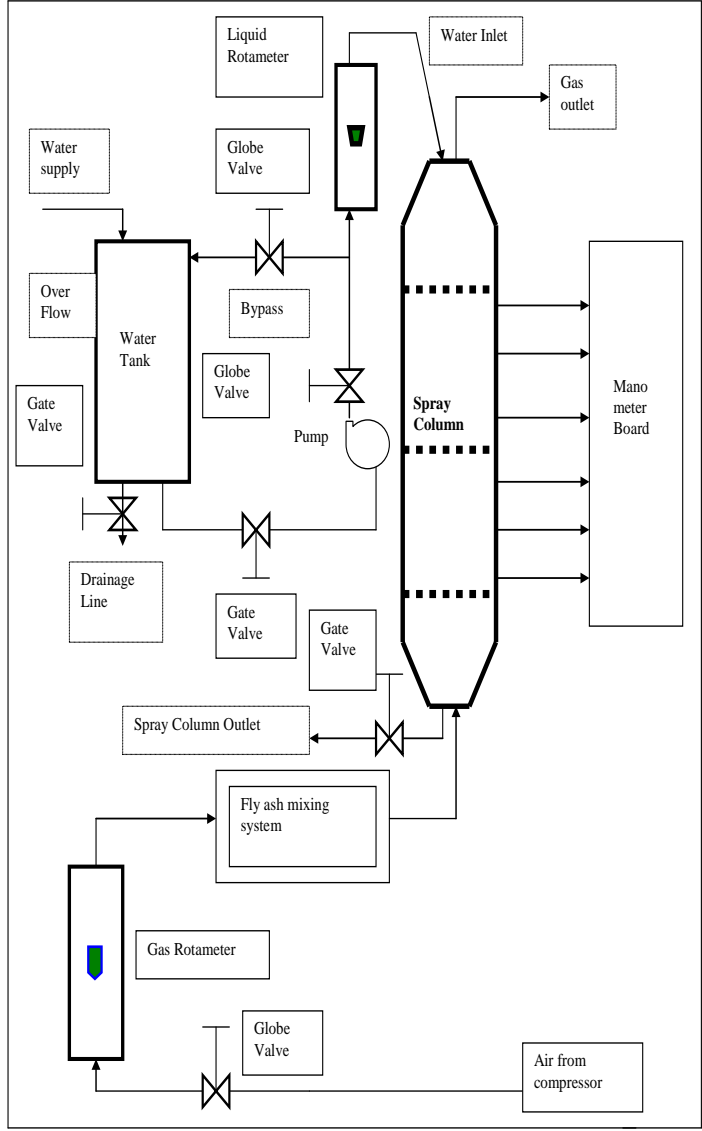

Fig. (3). Schematic diagram of the experimental setup.

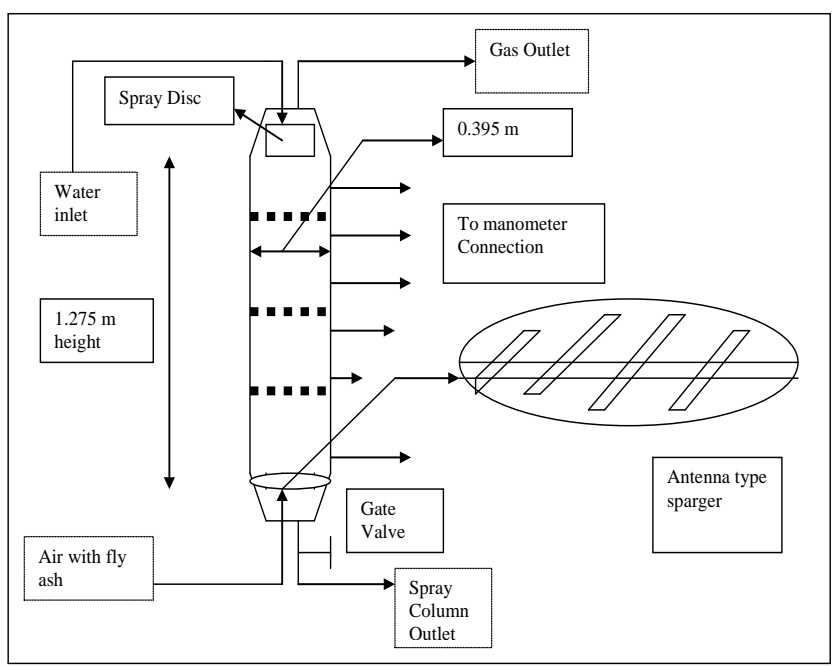

Fig. (4). Spray column with internals.

Along the cylindrical section, pressure tapings at every $25.5 \times 10^{-2} \mathrm{~m}$ apart are provided for manometers. At the top of the cylindrical section, some holes have been made in the fructo-conical section for the provision of out letting the air stream to pass out of the system. A spray disc having 100 apertures (1mm diameter each) at the top of this section is provided to supply water in the column in the form of uniform sprays. Fig. (5) shows the ejecting system consisting of an ejector, a solenoid valve, a fly ash pouring column. The 
ejector serves the purpose of fly ash mixing by creating a low pressure zone which causes suction of fly ash. The ejector is basically a perspex parallelopiped with length $0.10 \mathrm{~m}$, width $0.05 \mathrm{~m}$ and height $0.10 \mathrm{~m}$. The inlet and outlet channel diameters are $\left(1.27 \times 10^{-2} \mathrm{~m}\right.$ BSP Thread $)$ while it shrinks to $6.35 \mathrm{x} 10^{-3} \mathrm{~m}$. at the middle. The inlet is connected with the PVC pipe supplying air to the ejector and the outlet is connected with another PVC pipe to supply air stream mixed with fly ash. At the middle portion, to this shrinked part, another channel of $6.35 \times 10^{-3} \mathrm{~m}$ diameter is provided from the top of the ejector with an inclination angle of $60^{\circ}$. There is a perspex base of $2.54 \times 10^{-2} \mathrm{~m}$ thickness at the top of the ejector with a $1.27 \times 10^{-2} \mathrm{~m}$ BSP thread to provide connection with the solenoid valve.

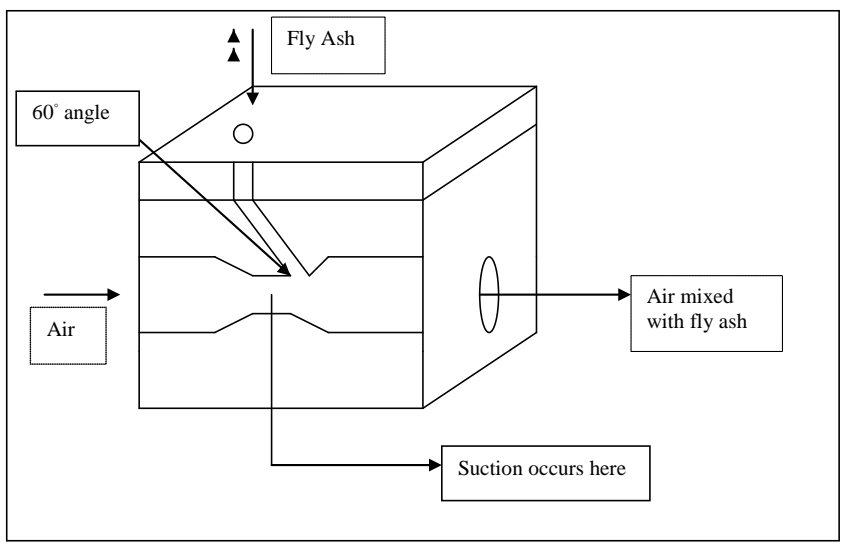

Fig. (5). Schematic representation of the ejector.

The fly ash pouring system made of perspex consists of a cylindrical column attached with a conical section. The cylindrical section is of height $0.71 \mathrm{~m}$. and diameter $0.15 \mathrm{~m}$ and the conical section is having top diameter $0.15 \mathrm{~m}$ and bottom diameter $3.05 \times 10^{-2} \mathrm{~m}$. The slant height is $2.286 \times 10^{-3} \mathrm{~m}$. At the end of the conical section, a solenoid valve is fixed to control the solids flow to the ejector. At the upper portion there is an arrangement of a $1.27 \times 10^{-2} \mathrm{~m}$ diameter aperture to pour fly ash into the column.

The system works on the counter current interaction of gas mixed with fly ash and the liquid, here it is water. The process can be illustrated in the following steps.

Air from the compressor supplied to the fly ash mixing system i.e. the ejector. And the fly ash is mixed with air due to suction in the ejector. The air flow rate is measured using a gas rotameter in the air supply line. The air along with the fly ash is fed into the column by an antenna type sparger. The merit of using " antena type sparger" is that it produces uniform bubble generation throughout the scrubber. A fructo-conical section at the top of the spray column serves as an outlet for the treated gas.

Water from the storage tank pumped into the top of the spray column and the flow measured by a liquid rotameter. A bypass line is also made in the water line for returning to the water storage tank. A stainless steel shower is fixed at the end of the water into the spray column to produce fine droplets. A water outlet line is at the bottom of the spray column to remove the fly ash mixed water. The fly ash concentrations at the inlet and the outlet of the scrubber were meas- ured by filtration techniques matching the conditions of isokinetic sampling (Indian Standards, 1973) [12].

Fig. (2) shows the particle size distribution of fly ash sample. The particle size analysis of fly ash is done by a Malvern Analyzer. Malvern Analyzer basically performs the cumulative analysis of the particle size ranging from $5 \mu \mathrm{m}$ to $564 \mu \mathrm{m}$. The density of fly ash determined experimentally and found out to be $1.73 \mathrm{gm} / \mathrm{cc}$ (approx.)

\section{RESULTS AND DISCUSSION}

The ejector developed for mixing fly ash is checked for its performance by conducting experiments, by passing constant amount of solids to different gas flow rates through the ejector. Fig. (6) represents the mixing characteristics of the ejector. It reveals that, as the air flow rate increases the mixing rate also increases. The loss of fly ash in the pipe line to the spray column is also calculated in order know the true concentration of the fly ash in the gas stream at the inlet of the spray column. Fig. (7) illustrates the variation in the concentration of the fly ash with respect to air flow rate. On average, it was found that around $2 \%$ of fly ash fed remains in the pipe for every gas flow rate establishing almost linear relationship for flow rates higher than 8 liters/cubic meter. From the results obtained, it is clear that the mixing is nonlinearly related with the air flow rate and the curve has a positive slope. It supports the fact that mixing of fly ash increases both in rate and amount with the increase in air flow rate because increased air flow rate causes better suction by the ejector.

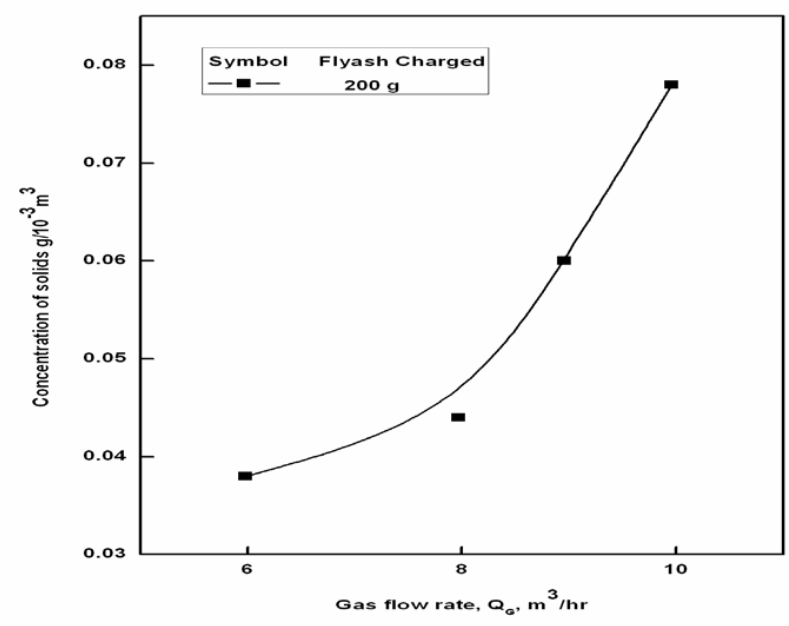

Fig. (6). Effect of gas flow rate on composition of fly ash.

The values of scrubbing efficiency of the spray column with internal are obtained at different gas and water flow rates and their plots distinctly shown in Figs. (7 and $\mathbf{8}$ ). Basically the efficiency depends on various parameters like the spray column height, particle size, droplet size, relative velocity between the particles and droplets, particle-particle interaction, surface tension of the liquid droplets etc. and certainly the mode of sending the fly ash mixed air to the spray column.

Fig. (8) shows that as the gas flow rate increases the scrubbing efficiency it also increases and reaches a maximum point and again falls back for the further increase in the 


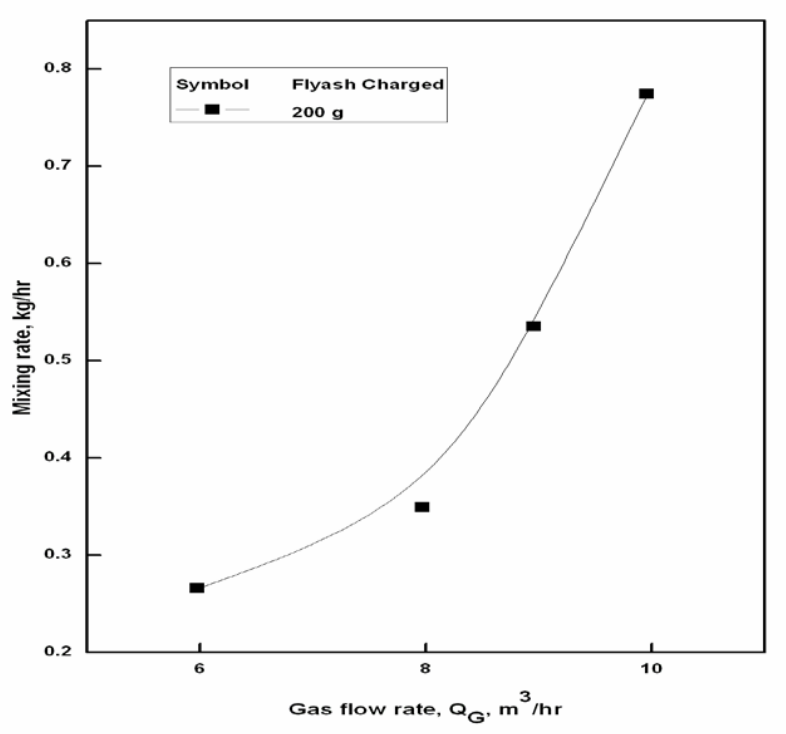

Fig. (7). Effect of gas flow rate on fly ash mixing rate in the ejector.

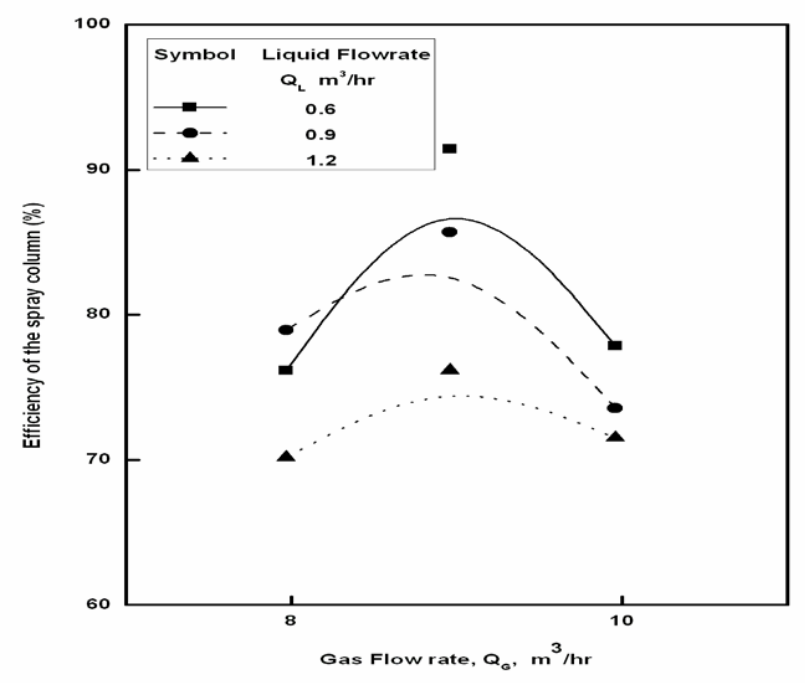

Fig. (8). Effect of the gas flow rate on scrubber efficiency.

gas flow rate. This reveals that an optimum relative velocity is set between the up flowing particles and down flowing droplets to achieve the maximum particle-droplet interaction and thereby to reach maximum efficiency. At $6 \times 10^{-2} \mathrm{~m}^{3} / \mathrm{hr}$ (constant) of liquid flow rate (water), when the dust laden gas flow rate is varied a maximum efficiency of $91 \%$ is achieved at around $8.96 \times 10^{-3} \mathrm{~m}^{3} / \mathrm{hr}$ and a further increase in the gas flow rate, a decrease in the efficiency is observed. Similarly, for higher liquid flow rates, $9 \times 10^{-2}$ and $120 \times 10^{-2}$ $\mathrm{m}^{3} / \mathrm{hr}$ there is an increase in the efficiency and a maximum efficiency of $85.71 \%$ and $76.17 \%$ respectively is reached at $8.96 \times 10^{-3} \mathrm{~m}^{3} / \mathrm{hr}$ of gas flow rate and further increase in the gas flow rate decreases the efficiency. Thus from the results it is clear that an optimum flow rates of gas and liquid in scrubbing the particulate matter using spray column with internals is found. Not necessarily, better fly ash input to the system will give better result. From the experiment, it has been obtained that maximum efficiency occurred neither at the highest value of fly ash input nor at the lowest, rather in between them. Regarding the water flow rates, lower flow rates gives more contact time with the particulates, more perfect droplets and also enhanced surface area of contact, whereas higher flow rates from the liquid distributor produces streams of liquid jets rather than droplets and hence the required relative velocity between the particles and the liquid in the form of liquid droplets fails to support the particle capturing mechanism leading to decrease in the efficiency. Fig. (9) represents the same efficiency variation with respect to liquid flow rate and further their relevant changes with respect to gas flow rate also. For gas flow rates $7.97 \mathrm{x}$ $10^{-3} \mathrm{~m}^{3} / \mathrm{hr}$ and $8.96 \times 10^{-3} \mathrm{~m}^{3} / \mathrm{hr}$ the maximum efficiencies are obtained at the initial liquid flow rate of $60 \times 10^{-3} \mathrm{~m}^{3} / \mathrm{hr}$ and further increase in the liquid flow rate decreases efficiencies, whereas for $9.96 \times 10^{-3} \mathrm{~m}^{3} / \mathrm{hr}$ gas flow rate the maximum efficiency is obtained at a liquid flow rate of $90 \mathrm{x}$ $10^{-3} \mathrm{~m}^{3} / \mathrm{hr}$. Thus relative velocity between the liquid droplets and particles play a crucial role in the scrubbing efficiency indicating that only for a definite range of relative velocities the scrubbing efficiency reaches the maximum.

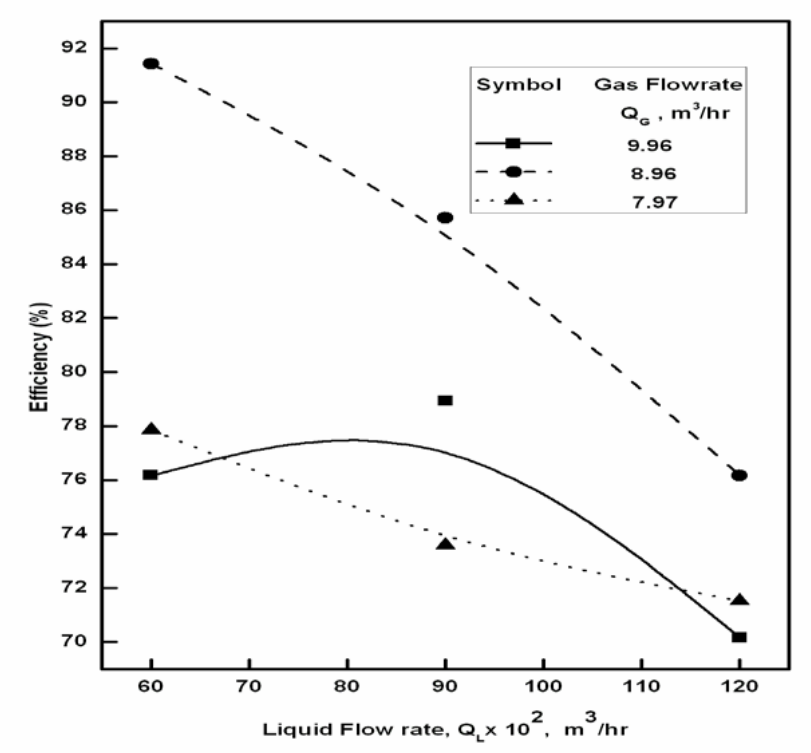

Fig. (9). Effect of the liquid flow rate on scrubber efficiency.

Fig. (10) represents the effect of liquid to gas ratio on the efficiency of scrubbing fly ash in the system. It is clear from the figure that an increase in the $\mathrm{Q}_{\mathrm{L}} / \mathrm{Q}_{\mathrm{G}}$ ratio decreases the efficiency. The particles that fail to encounter with the droplets due to the mismatch of the relative velocity range lead to the entrainment of the particles along with the gas stream, hence there is a decreasing trend in the efficiency.

\section{CONCLUSIONS}

Regarding the experiment, it was conducted for the air flow rate ranging between 9 to $6 \mathrm{~m}^{3} / \mathrm{hr}$ and particulate loading i.e. fly ash loading ranging from 13 to $4 \mathrm{gm} / \mathrm{min}$ respectively. The water flow rate was varied from 10 to 20 litre/minute. About the results, the efficiencies were found 
from 70 to $90 \%$. It was found to reach maximum at water flow rate $10 \mathrm{LPM}$ and air flow rate $8.96 \mathrm{~m}^{3} / \mathrm{hr}$.

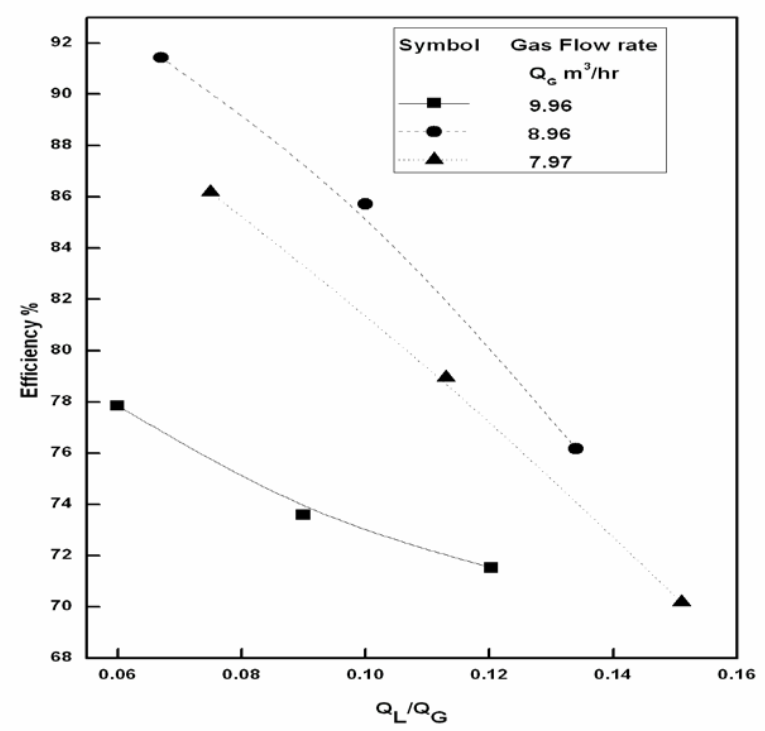

Fig. (10). Effect of liquid to gas ratio $\left(Q_{L} / Q_{G}\right)$ on scrubber efficiency.
This report has covered the literature study on wet scrubbing with an extra emphasis on spray scrubbing. It covers the detailed description and implementation of the scrubber. Along with this the report has tried to highlight not only on the harmful effects of fly ash as a pollutant but also its utilities through which the importance of fly ash removal from the industrial emissions becomes more prominent. It also gives an idea on the demand of the industries to meet the environmental regulations properly.

This project always aims to implement simple designs and not to use any type of accessories which are economically dear as well as sophisticated, because of enhancing its acceptability in the practical field. The experimental results which obtained from the project are satisfactory, still a miles to go by improving the system parameters. Further development of the scrubber can be made by incorporating better ejector design particularly suitable for fly ash (slurry type). Antenna type diffuser for sprinkling of liquid droplets can yield better result, because surface area of liquid droplets affects the contact with the particulate matters. Column height should be taken with care to get better contact time etc. The report ends with a further scope for experimental analysis and the deduction of the correlation among the different parameters of spray scrubbing.

\section{APPENDIX}

Table 1. Particle Size Distribution of the Fly Ash Sample (Using Malvern Analyzer)

\begin{tabular}{|c|c|c|}
\hline Particle size $(\mu \mathrm{m})$ & \% Under (cumulative) & \% In band \\
\hline \hline 188.00 & 100 & 0 \\
\hline 87.20 & 100 & 0.2 \\
\hline 53.50 & 100 & 2.3 \\
\hline 37.60 & 99.8 & 5.2 \\
\hline 28.10 & 96.5 & 5.3 \\
\hline 21.50 & 91.3 & 11.8 \\
\hline 16.70 & 86.0 & 11.8 \\
\hline 13.00 & 74.2 & 10.0 \\
\hline 10.10 & 62.4 & 11.6 \\
\hline 7.88 & 52.4 & 13.4 \\
\hline 6.15 & 40.8 & 11.7 \\
\hline 4.83 & 27.4 & 7.3 \\
\hline 3.80 & 16.7 & 4.1 \\
\hline 3.02 & 9.4 & 2.4 \\
\hline 2.41 & 5.3 & \\
\hline 1.94 & 2.9 & \\
\hline
\end{tabular}

Table 2. Mixing Performance of the Ejector

\begin{tabular}{|c|c|c|c|c|c|}
\hline Air flow rate $\left(\mathrm{m}^{3} / \mathbf{h r}\right)$ & Fly ash charged (gm) & Retained fly ash (gm) & Time (min) & Mixing rate $(\mathrm{kg} / \mathrm{hr})$ & $\begin{array}{l}\text { Mixing composition } \\
\text { (gm/liter of air) }\end{array}$ \\
\hline 9.96 & 200 & 135 & 5.04 & 0.774 & 0.078 \\
\hline 7.97 & 200 & 182 & 3.09 & 0.349 & 0.044 \\
\hline 5.98 & 200 & 191 & 2.03 & 0.266 & 0.038 \\
\hline
\end{tabular}


Table 3. Performance of the Scrubber

\begin{tabular}{|c|c|c|c|c|}
\hline Gas flow rate $\left(\mathrm{m}^{3} / \mathrm{hr}\right)$ & Water flow rate $\left(\mathrm{m}^{3} / \mathrm{hr}\right)$ & $\begin{array}{l}\text { Fly ash charged into the } \\
\text { spray column (gm/min) }\end{array}$ & $\begin{array}{c}\text { Fly ash obtained in } 10 \mathrm{ml} \\
\text { outlet sample (gm) }\end{array}$ & $\begin{array}{c}\text { Efficiency of the scrubber } \\
(\%)\end{array}$ \\
\hline 9.96 & 1.2 & 12.64 & 0.005 & 71.52 \\
\hline -do- & 0.6 & -do- & 0.010 & 77.85 \\
\hline 8.96 & 1.2 & 8.75 & 0.003 & 76.17 \\
\hline -do- & 0.6 & -do- & 0.008 & 91.43 \\
\hline 7.97 & 1.2 & 5.70 & 0.002 & 70.17 \\
\hline -do- & 0.9 & -do- & 0.003 & 78.94 \\
\hline -do- & 0.6 & -do- & 0.003 & 76.17 \\
\hline
\end{tabular}

\section{NOMENCLATURE}

$\mathrm{d}_{\mathrm{p}}=$ Particle diameter, $\mu \mathrm{m}$

$\mathrm{Q}_{\mathrm{G}}=$ Volumetric flow rate of gas, $\mathrm{m}^{3} / \mathrm{hr}$

$\mathrm{Q}_{\mathrm{L}}=$ Volumetric flow rate of liquid $\mathrm{m}^{3} / \mathrm{hr}$

\section{REFERENCES}

[1] B.C. Meikap, "Abatement of particulate laden sulfur dioxide in a modified multi-stage bubble column scrubber", $\mathrm{Ph}$. D. thesis, Indian Institute of Technology, Kharagpur, India, pp. 287-356, 2000.

[2] EPA, EPA's Clean Air Power Initiative, Office of Air and Radiation, US Environmental Protection Agency, Washington DC, Revision 2, June 1997.

[3] Pollution Prevention and Abatement Handbook, World Bank Environment Guidelines. Environment Department, USA 1995.

[4] B.C. Meikap, and M.N. Biswas, "Fly Ash Removal Efficiency in a Modified Multi-Stage Bubble Column Scrubber", Sep. Purif. Technol., Vol. 36(3), pp. 177-190, 2004.

[5] A.L. Kohl, and F.C. Reisenfeld, Gas purification, Gulf Publishing Company, Houston, Texas, USA, pp. 299-419 Chapter-7, 1985.
[6] A.D. Brandt, "Discussion on Pease-Anthony Venturi Scrubbers", In: W.P. Jones and A.W. Anthony Jr., Eds. In Proc. U.S. Technical Conf. on Air Pollution. McGraw-Hill Book Co. Inc., New York, USA, Chapter 39, pp. 327-329, 1952.

[7] A. Burkholz, Droplet Separation, VCH Verlagsgesellschaft, Weinheim (Federal Republic of Germany) and VCH Publishers, New York, USA, 1989.

[8] B.C. Meikap, G. Kundu, and M.N. Biswas, "Prediction of dispersed phase holdup in a modified multi-stage bubble column scrubber", Can. J. Chem. Eng., Vol. 80, pp. 1-7, 2002.

[9] B.C. Meikap, G. Kundu, and M.N. Biswas, "Modeling of a novel multi-stage bubble column scrubber for flue gas de-sulfurization", Chem. Eng. J., Vol. 86, pp. 331-342, 2002.

[10] B.C. Meikap, G. Kundu, and M.N. Biswas, "Scrubbing of fly-ash laden $\mathrm{SO}_{2}$ in a modified multi-stage bubble column scrubber", AIChE J., Vol. 48(8), pp. 2074-2083, 2002.

[11] B.C. Meikap, G. Kundu, and M.N. Biswas, "Thermal power plantsPollution control", Chem. Eng. World, Vol. 37(2), pp. 71-74, 2002.

[12] Indian Standards, Method for measurement of air pollution, IS: 5182, Part IV, Suspended Particulate, New Delhi 1973, pp. 3-12.

(C) Biswas et al.; Licensee Bentham Open.

This is an open access article licensed under the terms of the Creative Commons Attribution Non-Commercial License (http://creativecommons.org/licenses/by-nc/3.0/) which permits unrestricted, non-commercial use, distribution and reproduction in any medium, provided the work is properly cited. 